\title{
HYBRID MODEL FOR SOFTWARE DEVELOPMENT
}

\author{
Manju K Mathai ${ }^{1}$, Rakhi Venugopal ${ }^{2}$, John T Abraham ${ }^{3}$ \\ ${ }^{1}$ Asst.professor, Dept. of Computer Science, KMM College, Thrikkakera \\ manjukm84@gmail.com \\ ${ }^{2}$ Asst.professor, Dept. of Computer Science, MES College, Edathala \\ rakhivenu@gmail.com \\ ${ }^{3}$ Professor, Department of Computer Science Bharat Mata College, Thrikkakera \\ johntabraham@yahoo.com
}

\begin{abstract}
The methods used for conventional software development cannot be used directly for the development of web applications. Today most of the companies use scrum methodology for the development of web applications. But it seem to be difficult to use the scrum in large projects because of the change of requirement late in the project and also it is difficult apply scrum in a big team. This paper identifies and analyses the various changes required in the scrum methodology to make them applicable for the large projects and reduce the cost.
\end{abstract}

Keywords: software development model, hybrid model, scrum methodology, prototype models

\section{INTRODUCTION}

To develop conventional software number of software models is available. The base of all these models is the waterfall model. Most of the software development companies use any of these models for their development. But these models cannot be applied for the development of web application. This is because changes occur in the web application frequently. Today scrum methodology is commonly used for the development of web application. But there will not be an exact structure for scrum methodology. Different companies use the scrum in different ways. This is because if any changes occur in the product backlog, late in the project, then the development team takes more time for the development after updating the sprint backlog. Therefore it is necessary to analyze all the requirements in the beginning. Active customer involvement is necessary for the better analysis of requirement. Prototype models can be used in the software development, if the requirements are difficult to identify in the beginning. Therefore I am trying to develop a hybrid model using prototype model in scrum methodology.

\section{HISTORY OF SOFTWARE DEVELOPMENT}

Software can be defined as a set of instructions to do a particular task up on execution by the processor. The first software was written in 1940. Later different softwares were developed and the development of these software passes through different stages. These stages that the software passes through during its development is called software development life cycle(SDLC).Earlier the computer was seen only in limited numbers and most of the companies do their job manually. But later the situation changed and most of the companies uses computers for their work and hence the need of software increases tremendously. Now the situation is different that small and fastest computers are available in market.so fastest and reliable software is needed to use in such computers.

To develop such reliable and efficient software different methods and methodologies are available. The first programming language developed was FORTRAN in 1957.It is good in handling numbers but is not suitable for business needs. So to cope up with the business needs COBOL was developed .Then John McCarthy of MIT developed LISP. It is suitable for artificial intelligence. After LISP pascal was developed which combines the features of COBOL and ALGOL.Then in 1972 C programming language was developed by DennisRitche. C uses the features of PASCAL but have some additional features to overcome the limitations of PASCAL. This make the c programing commonly used in development of software. In 1980 a new programing concept called object oriented concept was introduced.Using this object oriented concept a new language called c++ was developed. But we can't say that c++ is pure object oriented language. Sun microsystem developed another portable object oriented programming language called JAVA. Because of the portability feature java is used by most programmers to run their software on different platforms. The software developers can develop their software using the different methodologies to develop their software.

\section{AGILE METHODOLOGIES}

Today software companies are competing for their software.so inorder to survive in this competing environment they developers need to develop complex projects. The common difficulties that the developers faced during the development process are

- changing requirements: customer requirements are rapidly changing during the development. Most of the customers do not have a clear idea about their requirements at the 
beginning. Late changes make the programmersdifficult to do modifications.

- Lack of Customer involvement: customer communication is necessary to understand the requirements at the beginning. Lack of customer involvement leads to higher chances of project failure

So inorder to overcome these problems a new methodology called agile methodology must be developed. In the case of agile methodology, the software is delivered to the customer in different increments. So the customer is able see the software before completion. The different agile methodologies are

\section{Extreme programming}

Scrum

Agile modeling etc.

\section{LIMITATIONS OF AGILE METHODOLOGIES}

Agile development helps in quick delivery of software. But there are some limitations to apply agile methodologies.

- Agile methogologies are not suitable if the system needs much documentation.

- The success of the project depend up on support from the customer. If the customer is less available, the requirement cannot be gathered correcltly.

- Another problem is that the team must be composed of experienced ones

- Since there is no one to control the team, it is not suitable for large team.

- It is not suitable, if the team is in distributed environment.

\section{SCRUM METHODOLOGY}

Scrum is based on agile methodology and it deliver the software as increments in the form of sprints. Each sprint takes two to four weeks time. The output of each sprint is a functional product that can be delivered to the customer. The different actors in the scrum development are product owner, scrum team and the scrum master. The product owner analyzes the requirements and creates a product backlog. The whole functionality that is to be built is included in the product backlog. The product owner prioritizes the backlog. The team works based on the priority of requirements in the product backlog. The product owner can change the requirements in the product backlog whenever required. Another feature of scrum methodology is burndown chart. It shows the amount of work that is to be done within the next scheduled date. The scrummaster is the person who protect the team from distractions that block the team from developing software. During the sprint the team conducts daily meeting of 10-15 minutes. All team members are required to attend scrum meetings

\section{Roles in Scrum}

There are mainly 3 roles

1. Product owner: The product owner is responsible for analyzing the requirements and creating a product backlog. $\mathrm{He}$ is responsible for prioritizing the productlog.

2. Scrum master: ScrumMaster protect the team from outside distractions and help them to reach the goal.

3. Scrum team: The team is responsible for building the product. The team members must be experienced ones.

The last thing done in sprint is the sprint retrospective. Many teams will do it immediately after the sprint review. The entire team, including both the ScrumMaster and the product owner should participate in the retrospective. The ScrumMaster can facilitate this sprint retrospective meeting by asking everyone to just shout out ideas during the scrum.
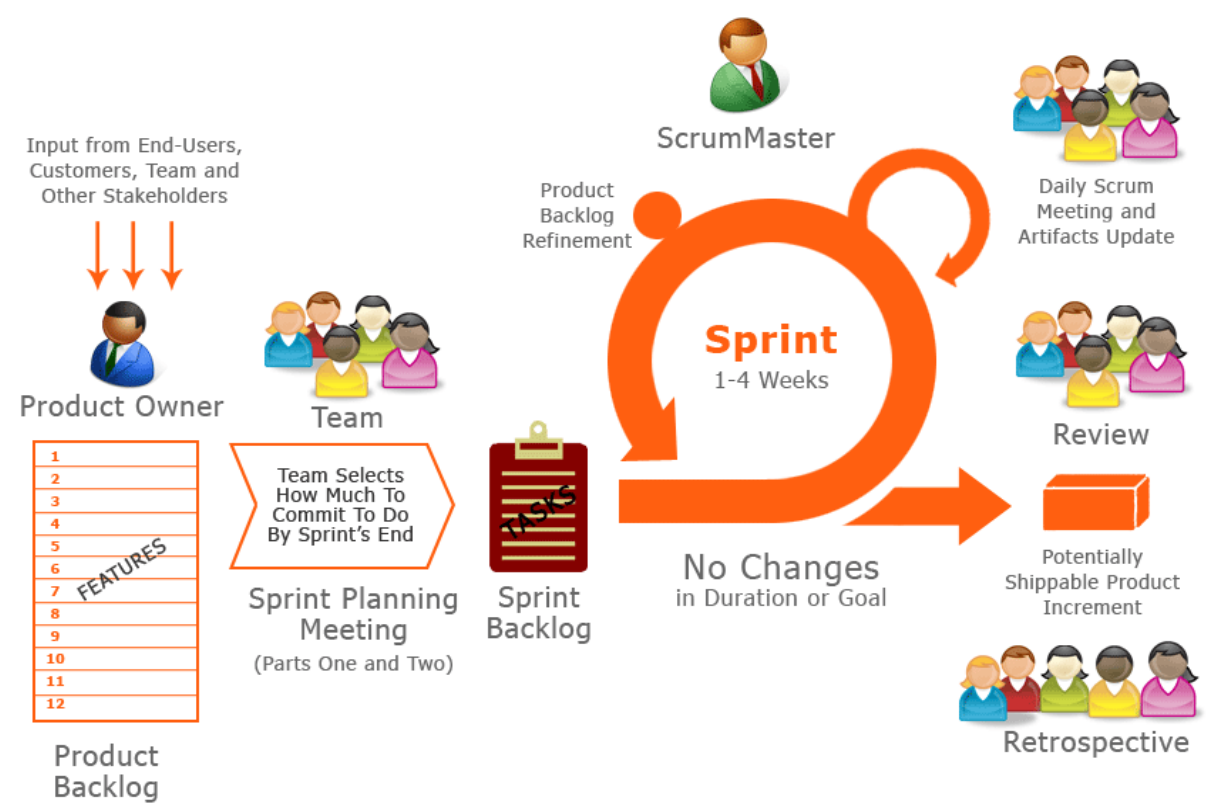

Fig-1. Scrum Framework 


\section{Advantages}

- Team gets an entire idea about the product before development.

- Accept the changes any time during the development.

- quick development of product.

- Able to develop product according to the priority of the requirements

- Never changes the schedule.

- Teams are self manageable.

- Work estimates are much easier

\section{Disadvantages}

- Documentation is very less

- Team members must be dedicated and experienced once.

- If team members does not cooperate well, the project will face failure

- Sometimes modification seems to be difficult after sprint release

- Necessary to get the requirements at the beginning

- Customers must have clear idea about the requirements.

The agile manifesto must follows PDCA cycle which was made popular by Dr. W. Edwards Deming. This process can be used to improve the product.

\section{PDCA AND SCRUM}

\section{Plan}

In this the team discusses the requirements and objectives. The team understands the goal and conditions for acceptance in this stage.

\section{Do}

The team work together to achieve the objectives they planed

\section{Check}

After each iteration the team conduct meetings to discuss the acceptance of product, whether the product had meet the planned objectives.

\section{Act}

If any deviation from the plan is observed, then the team brainstorms and does necessary things to prevent such deviations in future. This helps to provide better result in next iteration.

The process starts with a clear set of aim and acceptance criteria and the customer is happy because he can see the output quickly and can make the changes based on the market conditions.

\section{PROTOTYPE MODEL}

Prototype model should be used when all the requirements are not able to be specified in advance. In that case the development team develop a prototype with the known requirements and give it to the customer. The customer uses the prototype and specify the necessary modifications. Then the development team make the necessary changes and this process goes on continuously until the product is satisfied with the customer. That is in prototype model the customer is actively involved throughout the development. So if the development of desired product requires a lot of interaction with the customer and if the requirements are unknown then prototype model is the best.

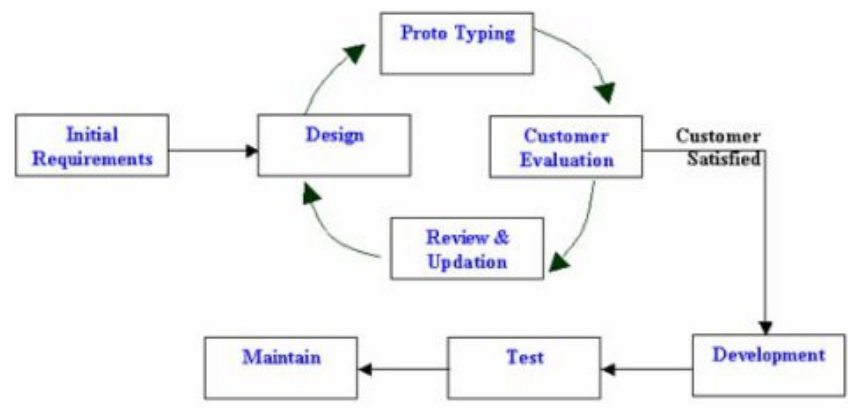

Fig-2 Prototype Model

Mainly there are 2 types of prototypes they are

1. Throw away prototype

2. Evolutionary prototype

Throwaway Prototype: After identifying the requirements, the team develop a prototype and give to the user. The user uses and specifies necessary modifications to the team. Then the team is responsible to do necessary modifications and this process goes on unit the product is accepted by the customer. If the product is accepted then the prototype is thrown and start developing the product from the beginning.

Evolutionary Prototypes: prototypes that evolve into the final system through iterative incorporation of user feedback.

\section{Advantages}

- Users are actively involved in the development

- Customers get a clear picture about the product before completion.

- Start development even if the requirements are not known in advance

- Less modification after the development of final product.

\section{THE PROPOSED HYBRID MODEL}

The proposed hybrid model is developed to solve the drawbacks of scrum methodology by incorporating the prototype model in scrum. 


\section{Difficulties in Scrum Development}

- Before the development, the team creates a sprint log for full product and start developing. The customer can make changes any time which in turn change the sprint backlog. So a lot of time is wasted to update the sprint backlog while developing. Sometimes they need to stop the entire work and starts from the beginning.

- When the team is in distributed environment, it may be difficult for him to conduct daily meeting (In the case of work at home, it is not possible for the person to physically present).

In different roles in proposed model are

1. Product owner

2. Scrum master

3. Scrum team

Product Owner: product owner has the vision of how to develop the product. He analyze and prioritize the requirements and develop the product log.

Scrum Master: He is responsible for removing any difficulties that are faced by the development team. He is responsible for guiding the team, building a trustworthy environment within the team facilitating discussions negotiation - communications and removing impediments and problems.

Scrum Team:Team is responsible for direct communication with the customer. They develop the product in different iteration by developing the prototype and give it to the customers for use. The team must be self manageable and must be dedicated to their work.

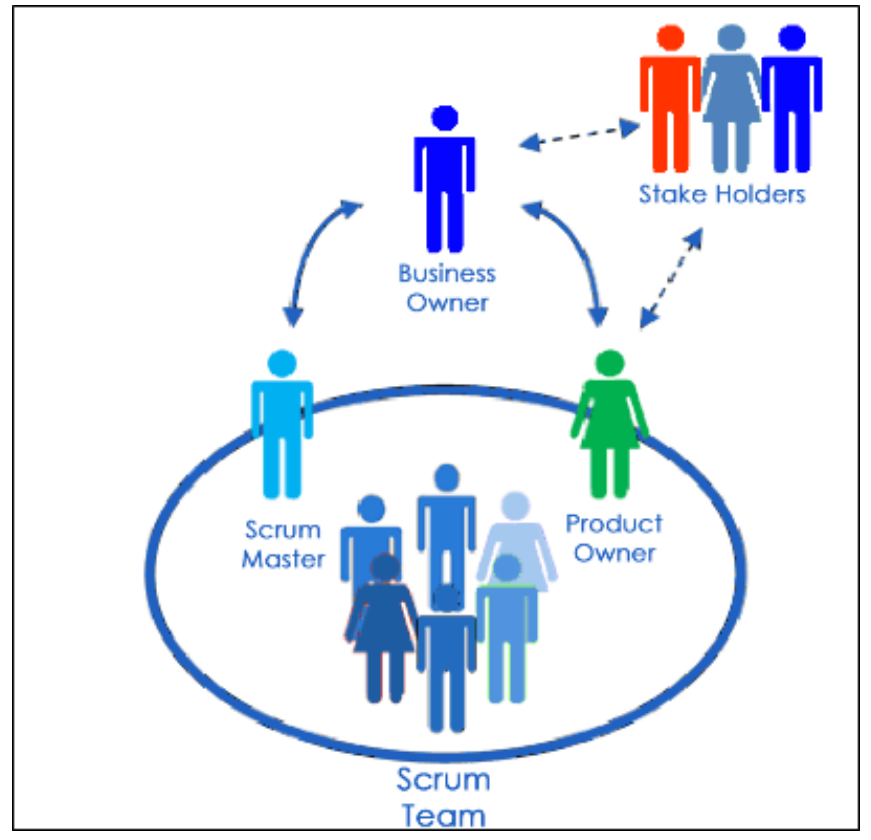

Fig- 3. Interrelationships between the stakeholders:

\section{Steps in proposed system}

1. Analyze requirements by product owner

2. Prepare product backlog by product owner

3. Prepare sprint backlog by scrum team

4. Develop a working prototype of the product by team

5. Release the prototype to the product owner and customer

6. Development of $1^{\text {st }}$ iteration product

7. Demonstration and review(include team, scrum master and product owner)

8. Release product to Product owner and the product owner release it to customer

9. Update sprint backlog if any

10. Start next sprint by developing the working prototype

11. Release complete product to customer

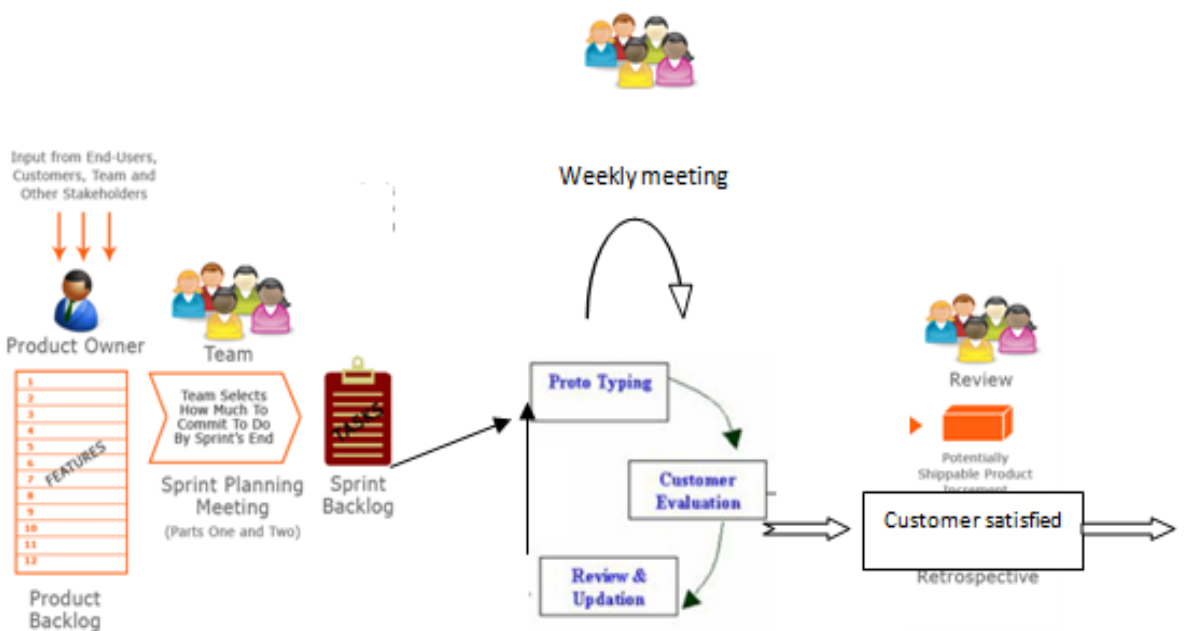

Fig-4. Hybrid Model 
Here the requirements are analyzed by the product owner and the product owner creates a product backlog. He may be able to prioritize the product any time. The team then creates a sprint $\log$. After the sprint $\log$ is accepted by the customer, the actual development begins.

The team starts working by developing a prototype of $1^{\text {st }}$ iteration and given to the customer for use. The customer can make any suggestions and modifications goes on until the final product is released. The prototype used is evolutionary type so time is not wasted do develop it again. So the customer is actively involves in the development. Since the customer uses the product while developing the number of changes after the release of first sprint is less.

Also the daily meeting is omitted here and the meeting can be arranged on weekly basis or in the middle of the sprint. This is because when the meeting is conducted daily, sometimes they don't have to speak anything. And if it is conducted on weekly or in the middle of the sprint all should have something to speak. So it helps to save time by avoiding the unnecessary meetings.

\section{CONCLUSION AND FUTURE WORK}

This paper analyses the difficulties while using scrum and develop a new hybrid model by integrating prototype model in scrum methodology. This helps to provide a structure to the web application development and late modification in the project and thus helps to use it in complex application. As a future enhancement we can add additional functionalities and may be able to develop a new model.

\section{REFERENCES}

[1] QURAT-UL-AIN, A HYBRID MODEL BY INTEGRATING SCRUM AND RAD, VAWKUM Transaction on Computer Science http://vfast.org/index.php/VTCS@ 2014 ISSN: 2308-8168 Volume 4, Number1, May-June, 2014

[2] Walter G. Barrios, Maria V. Godoy,Mirta G Fernandez, Sonia I Marino,Fernando M Ferreira and Cesar T Zarrabeitia ,Scrum: application experience in a software development PyME in the NEA, JCS\&T vol 12, No.3 october 2012

[3] Deemer P., Benefield G., Larman G. y Vodde B. (2010): The Scrum Primer. Scrum Training Institute. In http://assets.scrumtraininginstitute.com/downloads/1/ scrumprimer121.pdf.

[4] Ken Schwaber, Scrum development Process, Business Object Design and Implementation.

[5]Swaraj Gupta, Roles of team members involved in an AGILE Scrum project

[6] M. Mahalakshmi1, DR. M. Sundararajan, International Journal of Emerging Technology and Advanced Engineering, Volume 3, Issue 6, June 2013

[7] Ken Schwaber and Jeff Sutherland, "The Definitive Guide to Scrum: The Rules of the Game", The Scrum Guide, July 2011.

[8] MALIK HNEIF, 2SIEW HOCK OW, REVIEW OF AGILE METHODOLOGIES IN SOFTWARE DEVELOPMENT, International Journal of Research and
Reviews in Applied Sciences, Volume 1, Issue 1(October 2009)

[9] http://www.bizymoms.com/computers-andtechnology/software-development.html 